\section{Flow Analyzer for Blood Pump}

\section{By R.L. Rezer', M.A. Marciano' ${ }^{2}$ A.A. Santos, ${ }^{1}$ and W.K. Souza'}

Moinhos de Vento Hospital/Clinical Engineering, Porto Alegre, Brasil.

${ }^{2}$ Moinhos de Vento Hospital/Clinical and Hospital Engineering, Porto Alegre, Brasil.

\section{ABSTRACT} Medical equipment that supports life, relieves diseases, and overcomes disabilities can also cause damage and death due to
operational failures, user failures, and misuse. Hemodialysis machines include roller pumps that control the flow of blood, and operational failures, user failures, and misuse. Hemodialysis machines include roller
these pumps have to be calibrated accurately to ensure they are working properly.

This article describes the development of a low-cost, open source prototype that automates the flow analysis (measurement and This article describes the development of a low-cost, open source prototype that automates the flow analysis (measurement and
recording) of the blood pumps in hemodialysis machines. Being able to accurately inspect the machine's operation improves the quality and safety of its use. Through this technology (this process automation), it is believed equipment downtime and the quality and safety of its use.

This device has a system that collects data in real time, generated by the blood pump dialysis. Mathematical calculations are This device has a system that collects data in real time, generated by the blood pump dialysis. Mathematical calculations are
used to present flow information, including the standard deviation of the measurement, which is reported at the end of the test in an objective and simple way. Through a software and human machine interface (HMI), the test can be monitored and generate a report that contains the name and model of the equipment, the quantitative results of the lows, and the standard deviations maintenance, as a control practice making the calibration process easier and more cost-effective.

Keywords - Hemodialysis, Quality Control, Biomedical Analyzer, Arduino.

Copyright $\odot$ 2021. This is an open-access article distributed under the terms of the Creative Commons Attribution License (CC BY): Creative Commons - Attribuare credited and that the original publication in this journal is cited, in accordance with accepted academic practice. No use, distribution or reproduction is permitted which does not comply with these terms.

\section{INTRODUCTION}

Renal insufficiency occurs when the kidneys are unable to function properly. ${ }^{1}$ Hemodialysis is performed from a venous access allowing high blood flow. The blood is transported through an extracorporeal circulation system to a capillary filter, where it is purified and then returned to the body. It is usually performed three times a week, for an interval of three to four hours. ${ }^{2}$ Hemodialysis is susceptible to adverse events (AE) since it involves several risk factors, such as complications of invasive procedures, the use of complex equipment, critical patients, high patient turnover, and the administration of potentially dangerous drugs. ${ }^{3}$
The increasing use of hemodialysis worldwide is worrying specialists, researchers, managers, and health professionals. Data from the World Health Organization indicate that, annually, tens of millions of people worldwide suffer disabling injuries or death due to AEs following suffer disabling
hemodialysis.

Medical equipment that supports life, relieves diseases, and overcomes disabilities can also cause damag and death due to operational failures, user failures, and misuse ${ }^{5} \mathrm{Hem}$. misuse 5 due to operamp that control the flow of blood. The pumps should contain
various alarms and other devices to ensure patient safety.
Specific calibration is an important step for the correct operation of the equipment because the volume infused is the main parameter of the pump. It is essential that the methodology used in calibration be adequate for the tests to be validated as failure to do so can cause complications, to be valing us a including phlebitis, venous spasm, and pulmonary edema. ${ }^{6}$ The tests involve two parts - a qualitative evaluation (consisting of visual inspection of the structural conditions of equipment, parts, modules, and accessories) and quantitative tests (consisting of measuring or simulation of the parameters and/or the biomedical magnitude of the equipment). ${ }^{7}$ Some trials are still done manually making the process time-consuming and decreasing the availability of dialysis equipment in a busy center. The calibration of the rollers involves adjusting the distance between the roller and the rigid bed (occlusion). ${ }^{8}$ At present, to perform calibration of the blood pump assembly a precision scale, a graduated glass, and a digital timer are precision restrictions of this method are the uncertainties generated by the technical measurement process itself and the delay to carry out the measurements.

The main objective of this work is to develop a flow measurement device for blood pumps of hemodialysis machines. Whereas flows generated by hemodialysis machines are greater than $1200 \mathrm{~mL} / \mathrm{h}$ (maximum flow measured by the analyzers present in the market). The specific objectives to be achieved are (a) improving the precific objectives to be acheved are (a) inproving the Pececolited to the process of inspecting and testing quantitatively the equipment, and (d) improving the quality and safety of equipment use. For this development of the process automation, open source devices will be used, reducing the cost of the process.

\section{METHODS}

\section{Method Flow}

Figure 1 shows the flow of the steps followed for the development of this work. With the data specified, calculated, modeled, and simulated, the prototype was designed, developed, and tested.
Initially a group of studies was organized to evaluate possible solutions for a low-cost prototype for the blood pump flow analyzer. Several follow-ups were conducted at the hemodialysis center along with the nursing group to measure the real complications of the conventiona terional 1 , the other steps are described below.

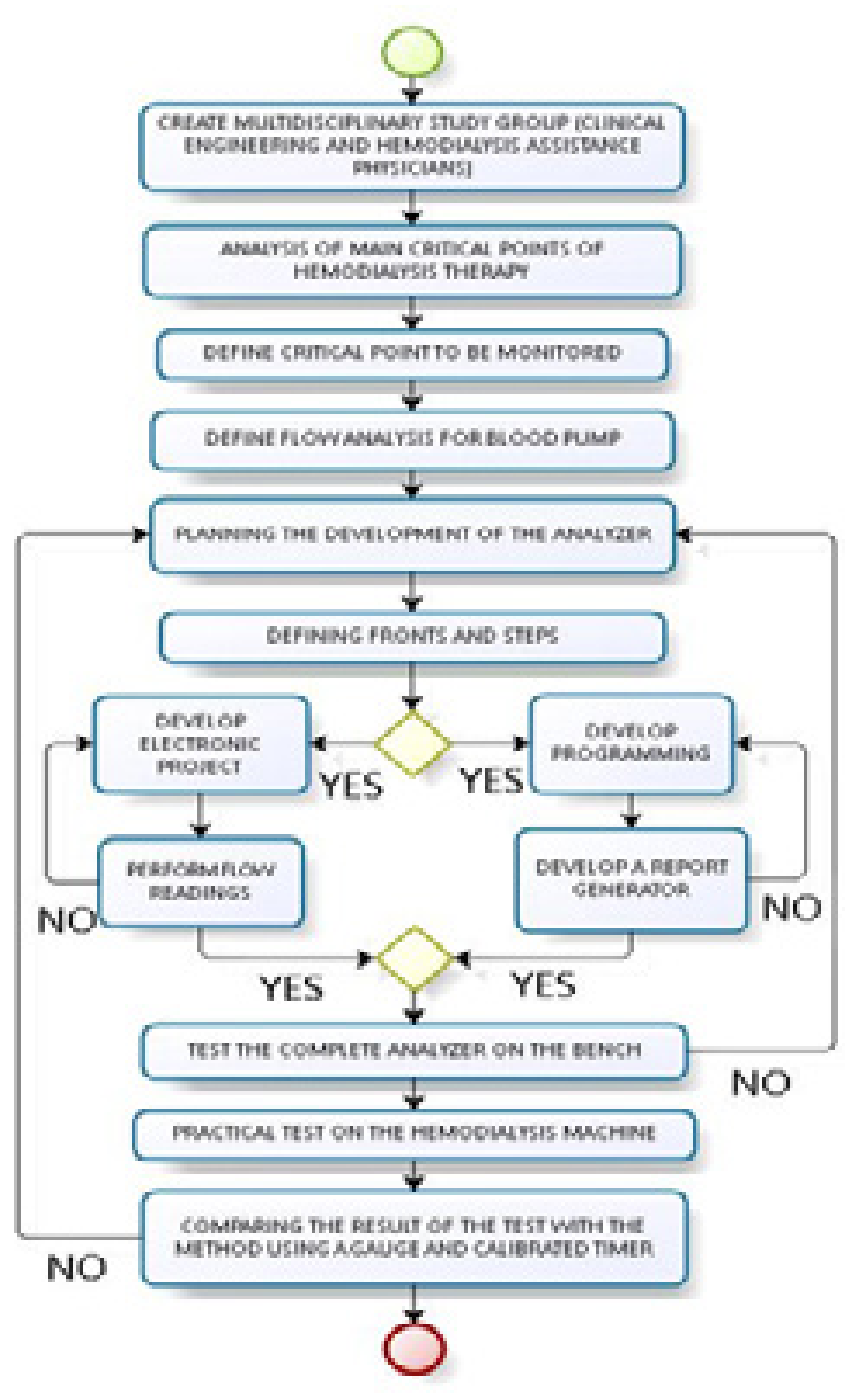

FIGURE 1. Flow of the working method.

In order to perform this stage, three calculations were used: one to generate the flow, another to generate the volume, and a third to determine the standard deviation, within the limits of the processor and the requirements to analyze the blood pump flow, according to the following equations: 


\section{Conversions}

Through the equations, Tables 1,2 , and 3 were developed with parameters for program development and report generator. The largest number of variables of the circular constant or Ludolph number (called " $\pi$ ", being $\pi=3.14159265$ ) was used to obtain the most accurate number possible.

$$
\begin{gathered}
v=h \pi r^{2} \\
Q=\frac{\text { volume }}{\text { time }} \\
S=\sqrt{\frac{\sum_{i=1}^{n}\left(x_{i}-\bar{x}\right)}{n-1}}
\end{gathered}
$$

TABLE 1. Conversion - Relation between Height ( $\mathrm{cm}$ ) and Volume (mL) in the Recipient

\begin{tabular}{|c|c|c|}
\hline \multicolumn{3}{|c|}{$(\mathbf{1}) \mathbf{v}=\mathbf{h} \pi \mathbf{r}^{2}$} \\
\hline $\begin{array}{c}\text { Direct Reading } \\
\text { Container }(\mathbf{m L})\end{array}$ & $\begin{array}{c}\text { Direct Reading } \\
\text { Height }(\mathbf{c m})\end{array}$ & $\begin{array}{c}\text { Calculated } \\
\text { Volume (mL) }\end{array}$ \\
\hline 0 & 0 & 0 \\
\hline 50 & 0.63665 & 50.00237407 \\
\hline 100 & 1.2733 & 100.0047481 \\
\hline 150 & 1.90995 & 150.0071222 \\
\hline 200 & 2.5466 & 200.0094963 \\
\hline 250 & 3.18325 & 250.0118704 \\
\hline 300 & 3.8199 & 300.0142444 \\
\hline
\end{tabular}

Considering $r=5.0000$

TABLE 2. Conversion - Relation between Volume (mL) and the Time (minute)

\begin{tabular}{|c|c|c|}
\hline \multicolumn{3}{|c|}{ (2) $\mathbf{Q}=$ volume/time } \\
\hline Volume (mL) & Time (minutes) & Flow (mL/min) \\
\hline 50 & 1 & 50 \\
\hline 300 & 6 & 50 \\
\hline 600 & 12 & 50 \\
\hline
\end{tabular}

This table represents the analysis of a flow of $50 \mathrm{~mL} /$ minute.

\begin{tabular}{|c|c|c|}
\hline \multicolumn{3}{|c|}{ Range of $50 \mathrm{~mL} /$ Minute } \\
\hline \multicolumn{3}{|c|}{ (3) $S=\sqrt{\frac{\sum_{i-1}^{n}\left(x_{i}-\bar{x}\right)}{n-1}}$} \\
\hline $\begin{array}{l}\text { Reading } \\
\text { numbers }\end{array}$ & $\begin{array}{l}\text { Flow } \\
(\mathrm{mL} / \mathrm{min})\end{array}$ & $\begin{array}{c}\text { Standard deviation } \\
(\mathrm{mL} / \mathrm{min})\end{array}$ \\
\hline 1 & 51 & \multirow{5}{*}{1} \\
\hline 2 & 50 & \\
\hline 3 & 49 & \\
\hline 4 & 51 & \\
\hline 5 & 49 & \\
\hline
\end{tabular}

TABLE 3. Conversion - Relation between Flow Readings and the Standard Deviation of the Readings Performed in the

Programming

At this stage the Arduino platform was programmed (Figure 2), with a $\mathrm{C}$ language principle. Based on Tables 1 and 2 , the volume and flow were described in the program. After this stage, the ultrasound sensor signal was programmed, making it a height meter to detect the volume of water and the valve, as a mechanism for releasing the water from the container in order to keep the blood pump always on, without overflowing the graduated containe The maximum level of volume was limited to $800 \mathrm{~mL}$, and the minimum was $50 \mathrm{~mL}$ for the beginning of the readings.

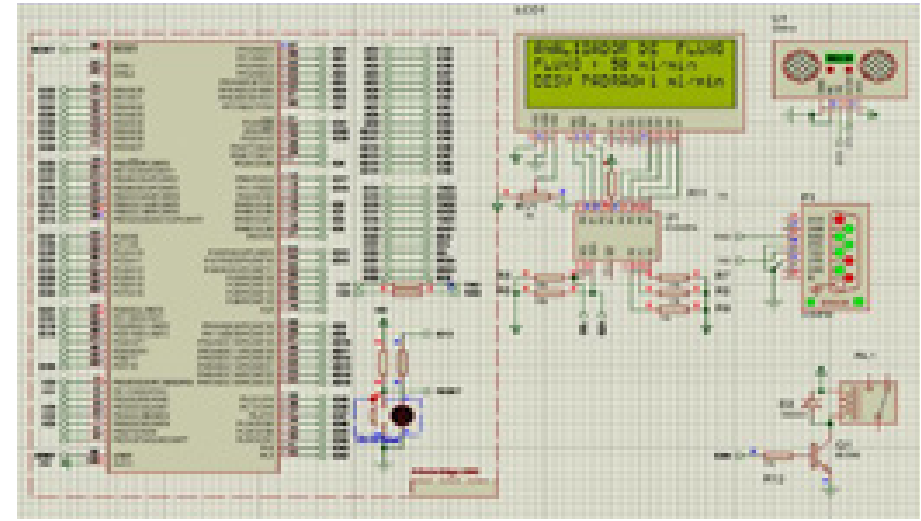

FIGURE 2. Electronic diagram of the circuit with the Arduino Platform.

Finally, the serial port was programmed where the name of the technician, the type of equipment, and the date and time of the service execution were introduced. On the display it shows only the flow values and the standard deviation. Figure 3 shows the flow and standard deviation in the display, data transmitted by the serial port and the final report.

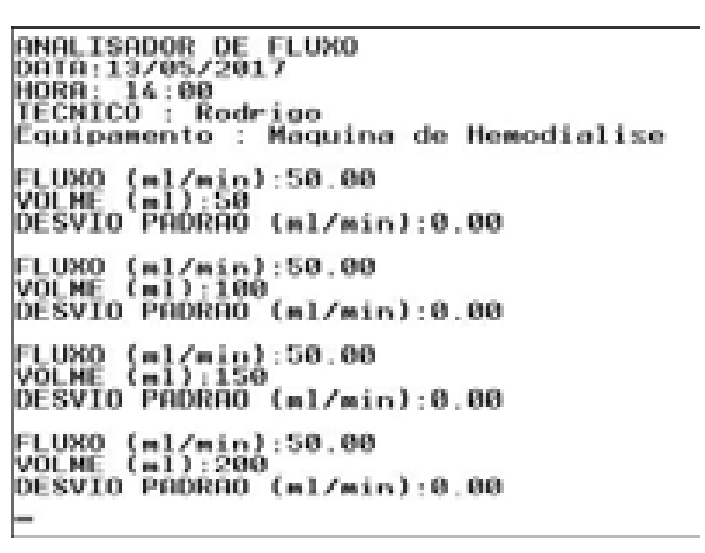

FIGURE 3. Data shown on the serial output.

\section{MATERIALS}

Peripherals

Peripherals installation - The system used a selector switch. The power to the board and the peripherals was through a computer source. For the control of the electromechanical device (valve), which is responsible for the release of water from the container, a normally open $5 \mathrm{~V}$ relay was used. The ultrasound sensor (HC-SR04) was applied to read the height of the water in the container, connected directly to the Arduino's inlet. The display uses I2C communication to transmit data from the Arduino to the HMI (Human Machine Interface). We used a serial output for communication of the Arduino with the computer. We can see the circuit of the project in Figure 2 .

Microcontroller

The Arduino Mega was used in this prototype, a free hardware and code platform that has its own compiler, designed to reach people who have little programming knowledge. The microcontroller used is the ATmel ATmega 2560, an 8-bit microcontroller of advanced RISC architecture. It has $256 \mathrm{~KB}$ Flash (plus $8 \mathrm{~KB}$ that are used for the bootloader), 8 KB RAM and 4 KB EEPROM. There are 16 MIPS, operating on $16 \mathrm{MHz}$ Arduino based on Atmel AT, operang on $16 \mathrm{MHz}$ Ard communication channels, 16 analog inputs and 15 PWM outputs. It has also SPI,12C communication and 6 pins for external interruptions. The Mega 2560 board has 54 pins of digital inputs and outputs that can be used as input or output. The pins operate at $5 \mathrm{~V}$ voltage and can supply or dich (pins A0 to A1 (pins A0 to A15), where the conversion can be made with a resolution of 10 bits, that is, the value will be converted between 0 and 1023 .

Ultrasound

The HC - SR04 ultrasound module provides 2 to $400 \mathrm{~cm}$ without contact and measuring function, with precision of $3 \mathrm{~mm}$.

HIM

In order for the simulator to have mobility and an easy interface between the operator and the device, it was decided to use the HMI system of the Arduino platform with I2C communication.

Power Supply

Standard 12V, 2.3A, real power of 500 Watts, efficiency $>70 \%$. TBF of 100,000 hours, $25^{\circ} \mathrm{C}$, internal protection against OVP / OCP / SCP short circuit, AC input with manual switching $110 / 220 \mathrm{~V}$, low acoustic noise, cable with protective cover, thermal cooling control system, 120 $\mathrm{mm}$ silent fan, technical standards IEC60950 (electrical safety), IEC61000 (electromagnetic safety) and On / Off switch.

Relay

$\mathrm{NA} / \mathrm{NF}$ of $5 \mathrm{~V}$.

Valve

Valve with $12 \mathrm{~V}$ solenoid.

Mechanical Assembly

For the assembly of the device, 5 threaded rods of $1 / 2$ with nut and washer were used, $150 \times 50 \mathrm{~cm}$ acrylic sheet, as shown in its assembly in figure 6 .

Container

A cylindrical container was used as a reservoir, graduated with a total volume of $1000 \mathrm{~mL}$ 
Flange

A flange of $1 / 2$ inch was attached to the bottom of the container for the water outlet.

Connector

A connector with the same diameter of the extender used in the conventional hemodialysis kit was installed for liquid inflow into the container.

\section{RESULTS}

To obtain the final results of the electronic part, the circuit was assembled. After the connection of the ultrasound sensor to the valve in the Arduino platform, four tests were performed and the analyzer responded satisfactorily. The final report is shown in Figure 3.

To obtain the final results of the mechanical part, the set was assembled as shown in Figure 4. After assembly of all electronic and mechanical parts, four tests were performed. With the design mounted, the set responded satisfactorily as shown in Figure 5 .

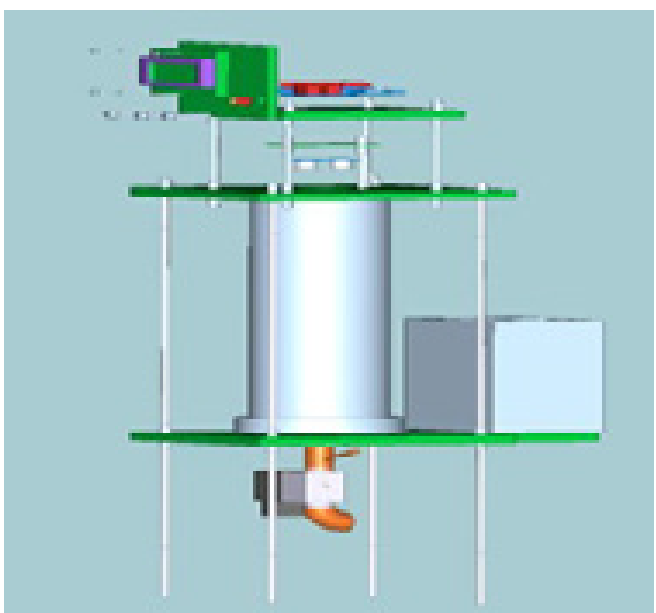

FIGURE 4. Mechanical design of the flow simulator for blood pumps.

After the complete assembly of the prototype in the initial verification form, bench tests were performed comparing the readings from this prototype with those from conventiona manual methods. After alladjustments, a test with the blood pump of the hemodialysis machine was performed. At the end of the test, a detailed analysis report was generated.

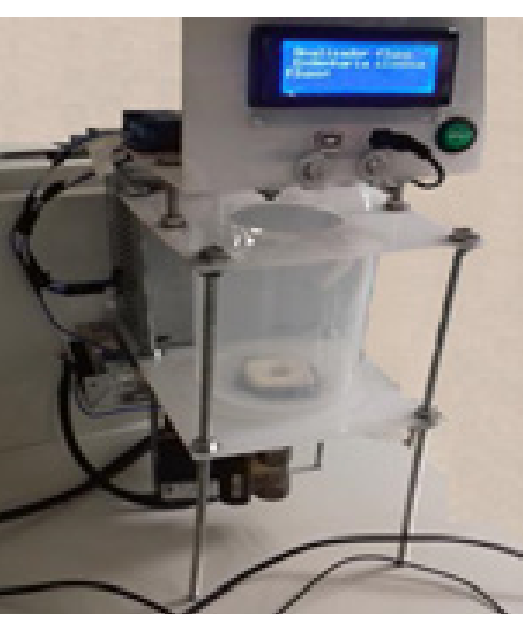

FIGURE 5. The final project.

\section{CONCLUSIONS}

Tools and support devices in the analysis and simulation of biomedical information are of great value in mitigating the risks related to the use of biomedical devices.

This article describes the development of an automated blood flow analyzer prototype to improve quality standards in the tests performed by clinical engineering services on hemodialysis machines. This prototype was found to reduce equipment downtime, reduce costs related to the testing process, and increase the safety of therapy with hospital devices that use blood pumps.

\section{CONFLICT OF INTEREST}

The authors declare that they have no conflict of interest.

\section{REFERENCES}

1. Ribeiro RCHM et al. Characterization and etiology of chronic renal failure in a nephrology unit in the interior of the State of São Paulo. Acta Paul. Enferm 2008;21(Special Issue):207-11.

2. Mariotti C. Quality of Life in Hemodialysis: Impact of an Occupational Therapy Program. Scand J Occupat The 2009;18(3):172-9.Curitiba Available at: http://dspace.c3s. ufpr.br:8080/dspace/bitstream/1884/21795/1/ Mariotti. pdf. Accessed on: May 2017.

3. Holley JL. A descriptive report of errors and adverse events in chronic hemodialysis units. Nephrol News Issues 2006;20(12)p.57-8; 60-1, 63.

4. ECRI - Emergency Care Research Institute. Digital consultation. [Internet] 2017. Available at: http://wwwecriorg/

5únior S. et al. System for evaluating the functionality of infusion pumps Brazil. 2004;17-19 pp.

6. Lucatelli MV. Proposal of Maintenance Application Focused on Reliability in Medical-Hospital Equipment. Florianópolis. 270f. Thesis (Doctorate in Information Systems) Graduate rogram in Electrical Engineering Federal University of Santa Catarina, Brazil. 2002.

7. Vlchek DL, Burrows-Hudson S and Pressly NA. Quality assurance guidelines for hemodialysis devices. HHS Publication FDA 1991;91(4161):233.

8. Tamari Y, Lee-Sensiba K, Leonard EF, Tortolani AJ. A dynamic method for setting roller pumps nonocclusively reduces hemolysis and predicts retrograde flow. ASAIO 1997;43(1):39-52.

9.Ausilio A. Arduino: A low-cost multipurpose lab equipment. Behav Res Methods 2012:44(2):305-13. 